\title{
Rapid brain death caused by a cerebellar abscess with Fusobacterium nucleatum in a young man with drug abuse: a case report
}

\author{
Gunnar TR Hischebeth ${ }^{1 *}$, Vera C Keil ${ }^{2}$, Katrin Gentil ${ }^{1}$, Azize Boström³ ${ }^{3}$ Klaus Kuchelmeister ${ }^{4}$ \\ and Isabelle Bekeredjian-Ding ${ }^{1}$
}

\begin{abstract}
Background: Fusobacterium nucleatum is a strict anaerobic microorganism that causes disease entities such as periodontal and soft tissue abscesses, pulmonary and intraabdominal infections and very rarely intracerebral infections.

Case presentation: Here, we report the rare case of a previously healthy 25 -year-old German man with a cerebellar abscess caused by Fusobacterium nucleatum that resulted in rapid brain death. Toxicological screening showed positivity for amphetamines and cannabis. The diagnosis was obtained by polymerase chain reaction amplification of bacterial deoxyribonucleic acid in cerebrospinal fluid.
\end{abstract}

Conclusions: In drug users clinicians should think about rare causes of brain abscesses/meningitis. Early diagnosis is necessary and justifies the use of molecular techniques.

Keywords: Fusobacterium nucleatum, Brain abscess, Brain death, Amphetamine abuse, 16s rDNA PCR

\section{Background}

Fusobacterium nucleatum is a strictly anaerobic microorganism that is indigenous to the human oral cavity, where it coexists with more than 500 other species [1]. It can also be found in the gastrointestinal, urogenital and upper respiratory tracts. It belongs to the family of Bacteroidaceae. Fusobacteria have a proteolytic metabolism with only low-level glucose acid-formation. Cells are gram negative rod-shaped with pointed ends.

Fusobacterium nucleatum has been reported to play a causative role in infections such as sinusitis, periodontal disease, pulmonary infections, intraabdominal infections, i.e. appendicitis and liver abscesses, and it was detected in a psoas abscess, septic arthritis, osteomyelitis and endocarditis [2-6]. Severe clinical courses, predominantly in adolescents, have been described. Clinical syndromes caused by Fusobacterium spp. are collectively referred to as

\footnotetext{
* Correspondence: hischebeth@microbiology-bonn.de

${ }^{1}$ Institute of Medical Microbiology, Immunology and Parasitology (IMMIP), University Hospital Bonn, Sigmund-Freud-Str. 25, D-53127 Bonn, Germany Full list of author information is available at the end of the article
}

necrobacillosis [7]. The literature documents that brain affection is, however, extremely rare [8-14].

\section{Case presentation}

Here we report the case of a 25-year-old German man, with no prior history of chronic illness or substance abuse. Nevertheless, toxicological screening was positive for cannabis and amphetamines. After a $72 \mathrm{~h}$ period of progressively increasing headache and psychiatric alteration he was admitted to a community hospital in a delirant state with somnolent phases. The patient was in good physical condition with aggressive fits, co-operative and orientated when awake and conscious and showed no signs of acute infection apart from an elevated C-reactive protein $(61.6 \mathrm{mg} / \mathrm{l})$ and leukocytes (21.6 G/l). Additional signs as fever, tachycardia or tachypnoe to diagnose severe inflammatory response syndrome (SIRS) were not seen. Upon physical examination there were no signs of meningism or impairment of motor or sensory function. Cranial nerve examination was discreet, pupils reactive to light and isocore.

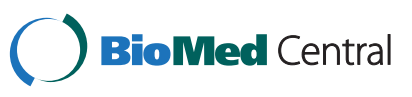

(c) 2014 Hischebeth et al.; licensee BioMed Central Ltd. This is an Open Access article distributed under the terms of the Creative Commons Attribution License (http://creativecommons.org/licenses/by/2.0), which permits unrestricted use, distribution, and reproduction in any medium, provided the original work is properly credited. The Creative Commons Public Domain Dedication waiver (http://creativecommons.org/publicdomain/zero/1.0/) applies to the data made available in this article, unless otherwise stated. 

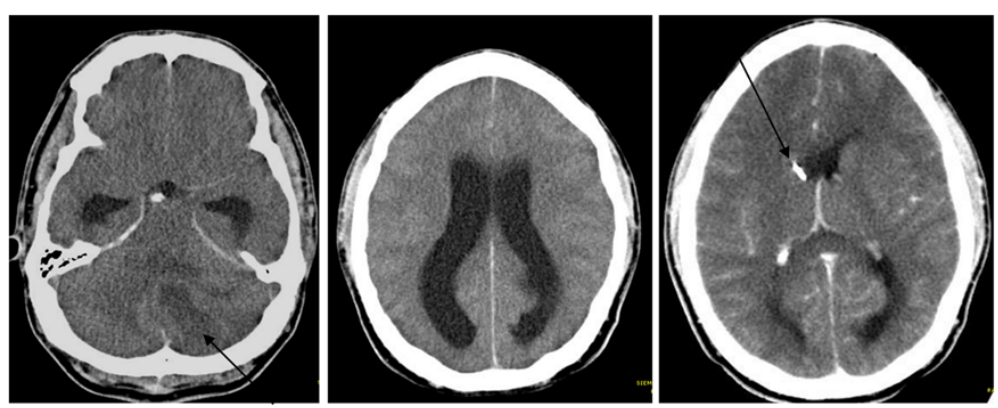

Figure 1 Computer tomography (CT) scan of the brain. CT scan of the cerebrum (left). White arrow indicates space occupying lesion. Cerebrum with widening of the side ventricles compatible with a hydrocephalus (middle) of the cerebrum after placement of an extraventricular drainage (EVD) (right). Black arrow indicates EVD in the side ventricle.

Clinical examination showed multiple scratches and infected pustules on both outer upper legs and arms. According to the family this situation had been longstanding and was not acute. The dermatologists classified these lesions as Prurigo subacuta. Six h after hospitalization the patient deteriorated rapidly to Glascow coma scale (GCS) 3 , was intubated and put on mechanical ventilation. Pupils were dilated. A native computer tomography $(\mathrm{CT})$ brain scan showed massive brain swelling with brain stem compression and a space occupying lesion (SOL) in the left cerebella hemisphere causing an occlusive hydrocephalus (Figure 1).

An external ventricular drainage (EVD) was inserted immediately and produced cerebrospinal fluid (CSF) under very high pressure. Cell counts and laboratory analysis of CSF showed increased polymorphic granulocytes (1116/ $\left.\mathrm{mm}^{3}\right)$, lymphocytes $\left(115 / \mathrm{mm}^{3}\right)$ and red blood cells $(3000 /$ $\mathrm{mm}^{3}$ ). The lactate and protein concentration was markedly elevated $(17 \mathrm{mmol} / \mathrm{l}$ and $12967.1 \mathrm{mg} / \mathrm{dl}$, respectively) and glucose levels were low $(<1 \mathrm{mg} / \mathrm{dl})$.

Despite these findings antibiotic therapy with flucloxacillin, ceftazidime and metronidazole had no clinical effect.
Microscopy of gram stained CSF specimen showed a massive number of leucocytes but no bacteria. Aerobic and anaerobic cultures were performed but remained negative. Specific polymerase chain reactions (PCR) excluded typical pathogens causing meningitis, e.g. Neisseria meningitides and Streptococcus pneumoniae $[15,16]$. However, a PCR product was detected with $16 \mathrm{~S}$ ribosomal deoxyribonucleic acid (rDNA) primers as previously described in [17]. PCR product sequencing detected genomic deoxyribonucleic acid (DNA) from Fusobacterium nucleatum with 98\% homology.

After the positioning of an EVD a CT brain scan with contrast agent was performed revealing no enhancement of the SOL but suspected occlusion of the basilar artery. The digital subtraction angiography (DSA) performed afterwards showed absence of perfusion compatible with brain death. Subsequently, an magnetic resonance imaging (MRI) was performed to complete the diagnostic imaging. Figure 2 documents abscess formation in the left cerebellum hemisphere. Despite maximal therapeutical effort to lower the intracerebral pressure reactivity of pupils could not be restored and brain stem reflexes vanished within
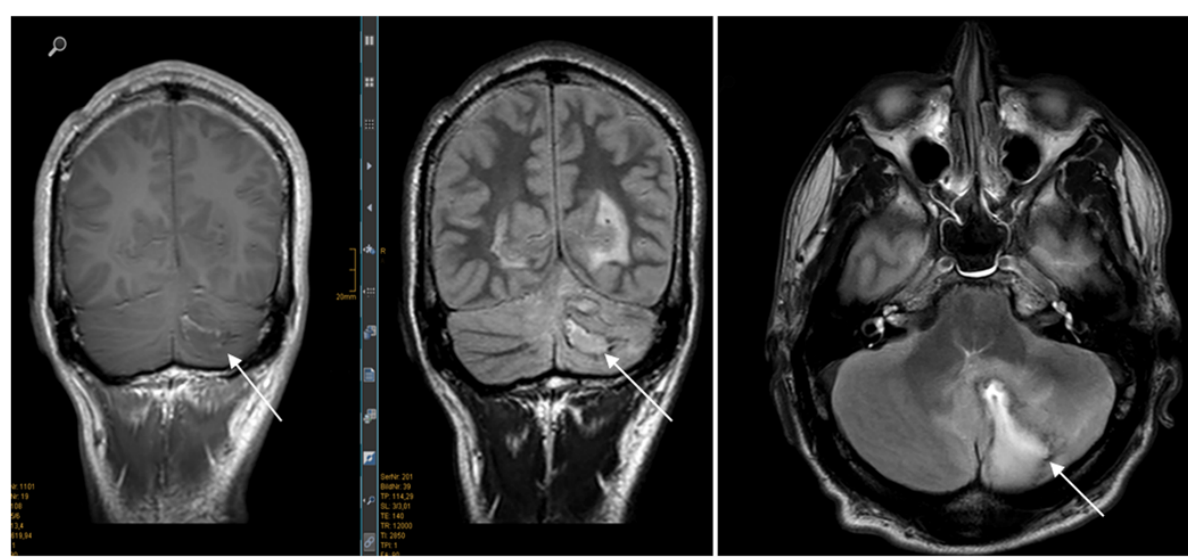

Figure 2 Magnetic resonance imaging (MRI) scan of the brain. T1 images with contrast medium (left and middle) and T2 images (right). White arrows indicate cerebellar abscess formation. 
Table 1 Summary of published reports on meningitis and brain abscesses caused by Fusobacterium nucleatum

\begin{tabular}{|c|c|c|c|c|c|c|}
\hline & Age/sex & $\begin{array}{l}\text { Surgical } \\
\text { treatment }\end{array}$ & Antibiotic therapy & Neurological symptoms & $\begin{array}{l}\text { Detection of } \\
\text { F. nucleatum }\end{array}$ & Therapeutic outcome \\
\hline Stefániková L et al. 2008 [18] & $41 / \mathrm{M}$ & NO & $\begin{array}{l}\text { cefotaxime, metronidazole, } \\
\text { subsequently co-trimoxazole } \\
\text { and rifampin }\end{array}$ & $\begin{array}{l}\text { headache, fever, slightly } \\
\text { hemiparesis of the right leg }\end{array}$ & PCR & survived, total recovery \\
\hline Kai A et al. 2008 [12] & $47 / \mathrm{M}$ & NO & ceftriaxone, metronidazole & $\begin{array}{l}\text { headache, neck pain, fever, vomiting, } \\
\text { transient loss of consciousness }\end{array}$ & culture & survived, total recovery \\
\hline Taguchi Y et al. 1981 [14] & 28/M & YES & penicillin $G$, chloramphenicol & pain left temporal region, general convulsion & culture & survived, total recovery \\
\hline Heckmann JG et al. 2003 [10] & $59 / F$ & NO & ceftriaxone, metronidazole & $\begin{array}{l}\text { confusion, neck stiffness, history } \\
\text { of moderate ethanol }\end{array}$ & PCR & survived, total recovery \\
\hline Keller PM et al. 2010 [13] & 29/M & YES & ceftriaxone, metronidazole & seizure, frontal headache & PCR & survived, residual chronic headache \\
\hline \multirow[t]{6}{*}{ Hsieh MJ et al. 2007 [1 1] } & $71 / F$ & YES & penicillin $\mathrm{G}$, chloramphenicol & $\begin{array}{l}\text { headache, fever, seizure, } \\
\text { visual disturbance, hemiparesis }\end{array}$ & culture & survived, hemiparesis \\
\hline & $58 / \mathrm{M}$ & YES & penicillin $\mathrm{G}$, metronidazole & $\begin{array}{l}\text { headache, fever, visual disturbance, } \\
\text { stiff neck }\end{array}$ & culture & $\begin{array}{l}\text { survived, hemiparesis, } \\
\text { homonymous hemianopia }\end{array}$ \\
\hline & 64/M & YES & penicillin $\mathrm{G}$, chloramphenicol & fever, seizure & culture & survived, total recovery \\
\hline & $34 / \mathrm{M}$ & YES & ceftriaxone, metronidazole & headache, fever, vomiting, stiff neck & culture & survived, total recovery \\
\hline & $52 / \mathrm{M}$ & YES & ceftriaxone, metronidazole & hemiparesis & culture & survived, wheelchair-bound \\
\hline & $51 / \mathrm{M}$ & YES & ceftriaxone, vancomycin, metronidazole & fever, consciousness disturbance & culture & survived, total recovery \\
\hline \multirow[t]{5}{*}{ Han XY et al. 2003 [9] } & 45/M & YES & penicillin G, metronidazole, ceftazidime & $\begin{array}{l}\text { headache, short term memory } \\
\text { loss, slurred speach }\end{array}$ & culture & survived \\
\hline & $56 / \mathrm{M}$ & YES & vancomycin, ceftazidime, metronidazole & $\begin{array}{l}\text { headache, confusion, disorientation, } \\
\text { left visual field deficits }\end{array}$ & culture & survived \\
\hline & 74/M & YES & vancomycin, metronidazole, cefepime & $\begin{array}{l}\text { garbled speech, incomplete } \\
\text { paresis of the right hand }\end{array}$ & culture & survived \\
\hline & $48 / \mathrm{M}$ & YES & ceftriaxone, metronidazole & $\begin{array}{l}\text { headache, speech difficulty, } \\
\text { confusion, memory loss }\end{array}$ & culture & survived \\
\hline & $59 / \mathrm{M}$ & YES & vancomycin, ceftazidime, metronidazole & memory loss, right-side weakness, aphasia & culture & survived \\
\hline
\end{tabular}


hours. Brain death was declared within 12 hours after the initial drop in GCS.

Pathological examination revealed an abscess in the left cerebella hemisphere with cerebellar oedema and brain stem herniation. There were signs of embolism of both main trunks of the pulmonary arteries. Microscopic analysis of the heart muscle showed hypereosinophilia as seen in necrosis and apoptosis.

\section{Discussion}

In the majority of cases aerobic pathogens are thought to be responsible for meningitis or brain abscesses. Nevertheless, over the last decades an increase in the detection of anaerobic pathogens causing meningitis has been observed. It is, however, unclear whether this is due to better processing of the specimen and increased sensitivity of detection methods. In the literature there are many reports about meningitis caused by anaerobes, but only about 30 reports on meningitis caused by Fusobacterium spp.. Overall, the incidence of brain infections caused by strictly anaerobic bacteria may have been underestimated in the past, and this neglect might account for delays in diagnosis or failure to identify the causative pathogen. Albeit several reports about brain abscesses caused by Fusobacterium nucleatum report successful recovery under conservative management, delay of effective antibiotic treatment can increase the severity of disease and lethality $[10,13,18]$.

Notably, one difficulty in our case was that the patient showed no typical signs for meningitis. Pathological examination confirmed this revealing only few immune cells infiltrating the meninges. Moreover, the patient showed symptoms that were well-compatible with drug intoxication. This might have contributed to the delay in the performance of the CT scan and the diagnosis. Next to the increased risk for abscess formation associated with intravenous drug abuse druginduced immune suppression (described for both amphetamine and cannaboids) might predispose for infections with unusual clinical course and symptoms $[19,20]$. Moreover, skin eruptions classified as Prurigo subacuta could originate from amphetamine abuse [21]. Radiological examination showed yet no classical enhancement pattern of contrast agent in the abscess border but a rather atypical abscess formation, thus making the differential diagnosis between abscess, tumor or hematoma difficult.

Previous studies report that only $6 \%$ of brain abscesses caused by bacteria arise from infection with Fusobacterium spp. [11]. A review of the literature showed that there are only few descriptions of Fusobacterium nucleatum brain abscesses with only seven papers and a total number of 16 patients documented in the MEDLINE. Table 1 summarizes the available reports about meningitis caused by Fusobacterium nucleatum. In contrast to the case presented here all other patients survived. The majority of patients received both surgery and antibiotic treatment. An interesting observation is that $87.5 \%$ of the patients reported were of male gender, but the reasons remain obscure. Diagnosis of Fusobacterium nucleatum infection in most cases was based on culture $(81.25 \%)$ and in only $18.75 \%$ on nucleic acid amplification techniques (NAT) [9-14,18]. Fourteen out of 16 culture positive specimens were derived from tissue samples or pus, which shows that an optimal culture result depends on the provision of an optimal specimen, such as tissue probes or pus obtained with invasive methods.

As PCR is not performed routinely in many laboratories it is likely that a certain percentage of cases remain undetected. PCR-mediated amplification and sequencing of $16 \mathrm{~S}$ ribosomal DNA might be of special usefulness in cases that remain negative in culture, possible due to prior antibiotic treatment or only low bacterial load such as that in the CSF of our patient. Notably, a biopsy of the brain abscess was not available during the short clinical course. As evidenced by the case presented in the absence of a suitable biopsy the use of NAT can enforce the diagnosis.

Until today many acute cases of inflammatory brain pathologies lead to death very rapidly. This case and the review of the literature show that - albeit rare - anaerobic microorganisms should not be disregarded in the differential diagnosis of intracranial infection and inflammation. Antibiotic therapy in brain inflammation should, therefore, cover anaerobic microorganisms. Drug abuse, including amphetamines and cannabinoids, predisposes for infections by suppressing immune function. Drug intoxication additionally obscures clinical symptoms relevant for diagnosis.

\section{Conclusion}

The widespread use of narcotic substances should, therefore, make us suspect of brain abscesses with rare pathogens in patients with unusual neurological symptoms. Severe cases, such as the one described in this study, justify early invasive procedures to obtain adequate specimen and rapid molecular approaches to obtain the diagnosis and initiate adequate treatment. Clinicians should stay in close contact with microbiologists to receive rapid results and therefore to launch sufficient therapy.

\section{Consent}

Written informed consent was obtained from the patient's father for publication of this Case Report and any accompanying images. A copy of the written consent is available for review by the Editor-in-Chief of this journal.

\section{Competing interests}

The authors declare that they have no competing interests.

\section{Authors' contributions}

$\mathrm{GH}$ and IBD wrote the manuscript. KG was involved in PCR diagnostic, VK and $A B$ have been involved in clinical treatment of the patient and $K K$ has been involved in post mortem pathological examination. $K G, V K, A B$ and $K K$ have been involved in critically revising the manuscript. All authors read and approved the final manuscript. 


\section{Acknowledgements}

The authors received no funding from external sources. We thank the family of the patient for agreeing to publish the case.

\section{Biographical sketch}

$\mathrm{GH}$ is resident physician in the Institute of Medical Microbiology, Immunology and Parasitology at the University Hospital Bonn, Germany. In his former career he acted as consultant for orthopaedic surgery. He is currently specializing in microbiology and combines these two main interests. He is investigating foreign body associated infections, especially orthopaedic prosthetic joint infections.

\section{Author details}

'Institute of Medical Microbiology, Immunology and Parasitology (IMMIP), University Hospital Bonn, Sigmund-Freud-Str. 25, D-53127 Bonn, Germany. ${ }^{2}$ Department of Radiology, University Hospital Bonn, Sigmund-Freud-Str. 25, D-53113 Bonn, Germany. ${ }^{3}$ Department of Neurosurgery, University Hospital Bonn, Sigmund-Freud-Str. 25, D-53113 Bonn, Germany. ${ }^{4}$ Institute of Neuropathology, University Hospital Bonn, Sigmund-Freud-Str. 25, D-53113 Bonn, Germany.

Received: 1 October 2013 Accepted: 3 June 2014

Published: 10 June 2014

\section{References}

1. Kolenbrander PE: Oral microbial communities: biofilms, interactions, and genetic systems. Annu Rev Microbiol 2000, 54:413-437.

2. Swidsinski A, Dorffel Y, Loening-Baucke V, Theissig F, Ruckert JC, Ismail M, Rau WA, Gaschler D, Weizenegger M, Kuhn S, Schilling J, Dörffel WV: Acute appendicitis is characterised by local invasion with Fusobacterium nucleatum/necrophorum. Gut 2011, 60(1):34-40.

3. Kim YH, Yoon HJ, Park CW, Kim JH, Lee MK, Kim KB, Na DJ, Kim JM: [A case of liver abscess caused by Fusobacterium nucleatum in a patient with recurrent periodontal diseases]. Korean J Gastroenterol 2011, 57(1):42-46.

4. Kroon E, Arents NA, Halbertsma FJ: Septic arthritis and osteomyelitis in a 10-year-old boy, caused by Fusobacterium nucleatum, diagnosed with PCR/16S ribosomal bacterial DNA amplification. BMJ Case Rep 2012, doi:10.1136/bcr.12.2011.5335.

5. Smetana GW: Primary psoas abscess due to Fusobacterium nucleatum. Scand J Infect Dis 1999, 31(3):319-321.

6. De Socio GV, Mencacci A, Bini P, Pasticci MB: Fusobacterium nucleatum endocarditis mimicking polymyalgia rheumatica. South Med J 2009, 102(10):1082-1084.

7. Eykyn SJ: Necrobacillosis. Scand J Infect Dis Supp/ 1989, 62:41-46.

8. Cahill DP, Barker FG 2nd, Davis KR, Kalva SP, Sahai I, Frosch MP: Case records of the Massachusetts General Hospital. Case 10-2010. A 37-yearold woman with weakness and a mass in the brain. N Engl J Med 2010, 362(14):1326-1333.

9. Han XY, Weinberg JS, Prabhu SS, Hassenbusch SJ, Fuller GN, Tarrand JJ, Kontoyiannis DP: Fusobacterial brain abscess: a review of five cases and an analysis of possible pathogenesis. J Neurosurg 2003, 99(4):693-700.

10. Heckmann JG, Lang CJ, Hartl H, Tomandl B: Multiple brain abscesses caused by Fusobacterium nucleatum treated conservatively. Can J Neurol Sci 2003, 30(3):266-268.

11. Hsieh MJ, Chang WN, Lui CC, Huang CR, Chuang YC, Chen SF, Li CS, Lu CH: Clinical characteristics of fusobacterial brain abscess. Jpn J Infect Dis 2007, 60(1):40-44.

12. Kai A, Cooke F, Antoun N, Siddharthan C, Sule O: A rare presentation of ventriculitis and brain abscess caused by Fusobacterium nucleatum. J Med Microbiol 2008, 57(Pt 5):668-671.

13. Keller PM, Rampini SK, Bloemberg GV: Detection of a mixed infection in a culture-negative brain abscess by broad-spectrum bacterial 16S rRNA gene PCR. J Clin Microbiol 2010, 48(6):2250-2252

14. Taguchi Y, Sato J, Nakamura N: Gas-containing brain abscess due to Fusobacterium nucleatum. Surg Neurol 1981, 16(6):408-410.

15. Corless CE, Guiver M, Borrow R, Edwards-Jones V, Fox AJ, Kaczmarski EB: Simultaneous detection of Neisseria meningitidis, Haemophilus influenzae, and Streptococcus pneumoniae in suspected cases of meningitis and septicemia using real-time PCR. J Clin Microbiol 2001, 39(4):1553-1558.

16. Carvalho Mda G, Tondella ML, McCaustland K, Weidlich L, McGee L, Mayer LW, Steigerwalt A, Whaley M, Facklam RR, Fields B, Carlone G, Ades EW, Dagan R,
Sampson JS: Evaluation and improvement of real-time PCR assays targeting lytA, ply, and psaA genes for detection of pneumococcal DNA. J Clin Microbiol 2007, 45(8):2460-2466.

17. Bekeredjian-Ding I, Foermer S, Kirschning CJ, Parcina M, Heeg K: Poke weed mitogen requires Toll-like receptor ligands for proliferative activity in human and murine B lymphocytes. PLoS One 2012, 7(1):e29806.

18. Stefanikova L, Freibergerova M, Husa P, Kerkovsky M: [Multiple brain abscesses of odontogenic origin caused by Fusobacterium nucleatum]. Klin Mikrobiol Infekc Lek 2008, 14(4):149-153.

19. Kaushik KS, Kapila K, Praharaj AK: Shooting up: the interface of microbial infections and drug abuse. J Med Microbiol 2011, 60(Pt 4):408-422.

20. Tunkel AR, Pradhan SK: Central nervous system infections in injection drug users. Infect Dis Clin North Am 2002, 16(3):589-605.

21. Sim MG, Hulse G, Khong E: Injecting drug use and skin lesions. Aust Fam Physician 2004, 33(7):519-522.

doi:10.1186/1756-0500-7-353

Cite this article as: Hischebeth et al:: Rapid brain death caused by a cerebellar abscess with Fusobacterium nucleatum in a young man with drug abuse: a case report. BMC Research Notes 2014 7:353.

\section{Submit your next manuscript to BioMed Central and take full advantage of:}

- Convenient online submission

- Thorough peer review

- No space constraints or color figure charges

- Immediate publication on acceptance

- Inclusion in PubMed, CAS, Scopus and Google Scholar

- Research which is freely available for redistribution

Submit your manuscript at www.biomedcentral.com/submit
C BioMed Central 